\title{
O papel da família nos planos de tratamento $e$ no cuidado pediátrico hospitalar em condições crônicas complexas de saúde
}

\section{The role of family in treatment plans and pediatric inpatient care in complex chronic health conditions}

\author{
Polyana Loureiro Martins ${ }^{a}$ \\ a Fundação Oswaldo Cruz. Instituto Nacional de Saúde da Mulher, \\ da Criança e do Adolescente Fernandes Figueira. Rio de Janeiro, \\ RJ, Brasil \\ E-mail: polyanaloureiroळhotmail.com \\ Creuza da Silva Azevedob

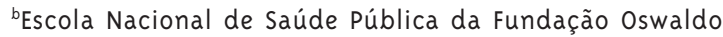 \\ Cruz. Instituto Nacional de Saúde da Mulher, da Criança e do \\ Adolescente Fernandes Figueira. Rio de Janeiro, RJ, Brasil. \\ E-mail: creuza®ensp.fiocruz.br

\section{Selene Beviláqua Chaves Afonso ${ }^{C}$} \\ ' Fundação Oswaldo Cruz. Instituto Nacional de Saúde da Mulher, \\ da Criança e do Adolescente Fernandes Figueira. Rio de Janeiro, \\ RJ, Brasil. \\ E-mail: selene.zero®gmail.com
}

\section{Correspondência}

Polyana Loureiro Martins

Rua Geraldo Martins, 155, ap. 603. Niterói, RJ, Brasil. CEP 24220-380.

\section{Resumo}

Este artigo examina o papel da família e a interação com profissionais na elaboração do plano de tratamento e na produção do cuidado com crianças em condições crônicas complexas de saúde numa unidade pediátrica de hospital de média e alta complexidade, referência no estado do Rio de Janeiro. Através de abordagem qualitativa, empregou-se a observação participante e entrevistas com mães de pacientes e gestores, analisadas por meio da abordagem da psicossociologia francesa. Os resultados apontam limites na inclusão dos familiares nas decisões e rumos do tratamento. Entre os profissionais, constatamos posicionamentos variados, sendo dominante o uso da comunicação de tipo informativo, empregada de forma irregular, que se intensificava quando havia decisões difíceis a serem tomadas. Em algumas situações também observou-se a capacidade de acolhimento ao familiar. Pouco do contexto psicossocial foi considerado. As mães tornavam-se responsáveis por tarefas técnicas da rotina de enfermagem, às quais acrescentavam o zelo e o carinho inerentes à maternagem. 0 reconhecimento do entrelaçamento das funções técnicas e de maternagem favorece a vitalidade e autonomia da mãe, mas também é fonte de angústia e de alta exigência psíquica. Por vezes, as mães são vistas como instrumento no cuidado, reduzindo-se seu espaço singular como sujeito.

Palavras-chave: Cuidado da Criança; Planejamento de Assistência ao Paciente; Subjetividade e Cuidado em Saúde; Doença Crônica; Família. 


\section{Introdução}

This article examines the family's role and the interaction with professionals when developing treatment plan and providing care for children with complex chronic health conditions in a pediatric unit of medium and high complexity, reference hospital in Rio de Janeiro state. Through a qualitative research, participant observation and interviews with patient's mothers and managers analyzed based on the French psychosociology were performed. The results point out limits in the inclusion of family members in decisions and directions of treatment. Among the professionals, we found different attitudes, in which communication with families by using irregular informational communication intensified when faced with difficult decisions to be made was predominant. In some situations, hospitality to the family member was observed. Little of the psychosocial context was considered. Mothers became responsible for technical tasks of the nursing routine, to which they added the zeal and affection inherent in mothering. Recognizing the combination between technical and mother's functions favors the mother's vitality and autonomy, but also causes anguish and considerable psychological pressure. Then, they were an instrument in care, reducing their singular space as subject.

Keywords: Child Care; Patient Care Planning; Subjectivity and Health Care; Chronic Disease; Family.
As crianças com condições crônicas complexas (CCC), termo ainda pouco definido, mesmo internacionalmente, apresentam fragilidades clínicas, altas taxas de morbidade e mortalidade e, portanto, necessidades de cuidados intensivos, que demandam adequações do atual modelo das ações de saúde. Essas condições, em parte, se devem ao incremento das taxas de sobrevivência de crianças prematuras, à atuação das unidades de terapia intensiva e aos avanços no campo da oncologia, que garantem a vida dessas crianças, mas resultam, por vezes, em complicações orgânicas e desabilidades para toda a vida (Cohen et al., 2011). Seja qual for a condição de base, a maioria delas demanda cuidados intensivos, dependência de tecnologia, uso de múltiplos medicamentos, home care e risco de frequentes e prolongadas hospitalizações que necessitam ações bem coordenadas (Costa; Gomes; Pinto, 2011). No Brasil, essas condições também se devem à transição epidemiológica e demandam uma nova lógica de cuidados, formação e capacitação de profissionais em busca de uma nova pediatria (Moreira; Gomes; Sá, 2014).

As famílias dessas crianças, em contato com essa condição de saúde, necessitam reorganizar sua dinâmica. O familiar responsável passa a conviver com o ambiente hospitalar por tempo prolongado e, muitas vezes, sem previsão de alta da criança, impõe-se um afastamento do seu meio social e do trabalho. Durante a internação hospitalar, o familiar desempenha papel fundamental não apenas para a criança, mas também para os profissionais de saúde, pois a equipe se dirige a ele para tratar questões sobre o manejo do cuidado e a troca de informações sobre a saúde da criança.

Nesse contexto, a família apreende novas referências que instrumentalizam o cuidar (Gomes; Erdmann, 2005). A rotina compreende o aprendizado de novas e diferentes formas de promover a alimentação, a higiene e a administração dos medicamentos, uma vez que essas tarefas envolvem atenção com a singularidade e a especificidade da criança e também podem demandar o uso de tecnologias. Apesar de esses pacientes tenderem a viver em condições precárias de saúde física, comportamental e emocional, e de 
representarem um desafio aos seus familiares, poucas pesquisas têm se dedicado a examinar essa condição e as iniciativas de enfrentamento do problema, identificando as necessidades da família que estará diante de um quadro de múltiplas deficiências, permanentemente (Cohen et al., 2011).

A medicina tradicional do século XIX construiu meios de investigar e classificar os sintomas e queixas dos pacientes a partir do relato de suas disfunções corporais. Esse modo de reconhecer o processo saúdedoença ainda é observado em práticas que restringem a consideração das questões sociais e subjetivas próprias de cada paciente, em meio ao excesso de preocupação com a detecção e enfrentamento dos sintomas.

A partir da ampliação do olhar sobre a clínica e propondo mudanças no modo de produção da assistência à saúde, constituiu-se em 2004 a Política Nacional de Humanização (PNH), que compreende a atenção em saúde como "ofertar atendimento de qualidade articulando os avanços tecnológicos com acolhimento, com a melhoria dos ambientes de cuidado e das condições de trabalho dos profissionais" (Brasil, 2004, p. 7). São destacados nesta política os aspectos interativos da clínica, a escuta e o reconhecimento da singularidade dos pacientes e seus familiares.

A perspectiva do cuidado integral, norteadora da mudança pretendida, pressupõe um modelo técnico-assistencial com transformações na relação de poder entre o profissional e o usuário, buscando alterar o que foi denominado como "cisão euoutro" no sentido de construção de uma "ética da diferença”, procurando integrar o outro (Teixeira, 2003). Buscando reconhecer a "sabedoria prática" do usuário e do familiar e a garantia de sua participação nas decisões, passam a ser valorizadas práticas de saúde em que as soluções são progressivamente negociadas através de contingências e imprevistos (Pinheiro; Silva Júnior, 2009). A construção da integralidade nas práticas de saúde transformadoras pauta-se, então, por uma perspectiva crítica ao tecnicismo e ao cientificismo, com valorização da sabedoria dos atores envolvidos em busca de um saber-fazer comum, no qual solidariedade e atitudes de cooperação são fundamentais para a construção de responsabilização (Pinheiro, 2007).

Compreendendo o cuidado em saúde como um valor e uma ação integral que "tem significados e sentidos voltados para a compreensão da saúde como direito do ser" (Pinheiro; Silva Júnior, 2009, p. 18), destacamos o estudo da organização do processo de trabalho em saúde, tendo como desafio permanente revalorizá-lo (Pinheiro, 2007).

Dessa maneira, o presente estudo busca compreender as tensões que concorrem para a inclusão de familiares de crianças em CCC na elaboração e implementação cotidiana dos planos de tratamento, considerando a ótica dos familiares, profissionais e gestores de uma unidade de pacientes internados (UPI) de um serviço de pediatria de alta e média complexidade de um hospital público do Rio de Janeiro.

A justificativa para o estudo está na promoção de uma reflexão sobre o papel da família e sobre a interação profissional-família na elaboração do plano de tratamento e na produção do cuidado, no contexto de alta complexidade do cuidado pediátrico. A investigação propõe dar ressonância à complexidade da recomendação da PNH quanto à ampliação do diálogo entre todos os segmentos envolvidos no processo de produção de saúde e contribuir para reforçar estratégias de bem cuidar no campo da saúde coletiva.

\section{Metodologia}

A pesquisa foi desenvolvida em uma UPI de um hospital de alta e média complexidade, no atendimento pediátrico a pacientes com CCC, no município do Rio de Janeiro, entre junho e agosto de 2014. Por meio de abordagem qualitativa, empregando-se observação participante e entrevistas com gestores e familiares, investigouse a participação familiar na construção do plano de tratamento. A observação participante foi uma estratégia profícua, por possibilitar proximidade ao objeto de estudo. Ela abrangeu o cotidiano do cuidado com os pacientes selecionados e os dispositivos de gestão assistencial que pudessem contribuir para construção dos planos de tratamento. Utilizou-se um diário de campo para registro das vivências do pesquisador e cenas de cuidado observadas. Foram realizadas entrevistas semiestruturadas com duas gestoras e quatro mães de crianças internadas, incluídas no estudo. As entrevistas foram gravadas, para maior fidedignidade (Minayo, 2013). 
A observação participante incluiu profissionais de saúde e familiares dos pacientes, considerando os seguintes critérios para inclusão de sujeitos: (1) profissionais de saúde de diferentes categorias: médicos, enfermeiros, técnicos de enfermagem, fisioterapeutas, nutricionistas, terapeutas ocupacionais, fonoaudiólogos, assistentes sociais e psicólogos, observados nas cenas de cuidado e nos dispositivos coletivos; (2) Familiares, sendo selecionados aqueles que atendiam critérios relativos a seus filhos. Para seleção das crianças/ pacientes e seus pais, adotamos o princípio da diversificação intragrupo, visando à descrição por variedade de tipos (Turato, 2008). Foram então incluídos pacientes com diferentes patologias, atendidos por diferentes equipes de referência.

Entrevistou-se, além dos familiares, os chefes de serviço, por serem informantes chave para compreensão da organização do cuidado e da construção dos planos de tratamento

Todas as crianças selecionadas para observação de cenas de cuidado apresentavam alguma dependência tecnológica e/ou necessidade de cuidados complexos de suporte respiratório, nutricional ou ambos.

Os pacientes selecionados foram observados em diferentes momentos da rotina hospitalar. O tempo de internação das crianças variava entre 3 meses e 1 ano e 7 meses. 0 cuidador principal dessas crianças na enfermaria era a mãe. Eventualmente havia revezamento, como no caso do paciente $\mathrm{A}$, com o pai, e dos pacientes B e D, com as avós.

O desenvolvimento e a análise da pesquisa foram realizados de acordo com a abordagem psicossociológica francesa, vertente da psicologia social que estuda sujeitos em situações cotidianas, em seus grupos e organizações (Enriquez, 1997; Sá; Azevedo, 2015). A leitura psicanalítica voltada para a noção de cuidado também foi referência teórica importante (Figueiredo, 2009; Winnicott, 1994). Sob esta perspectiva, a construção de conhecimento é fruto do processo de elaboração de sentido que envolve o pesquisador como sujeito em sua experiência de campo. Os fenômenos ou processos a estudar devem ser experienciados e interrogados pelo pesquisador para que possam ter significações, considerando a implicação do pesquisador como condição e caminho desta análise (Barus-Michel, 2004). Nesta construção, propõe-se um vai e vem entre situações concretas, a escuta sensível do pesquisador e a teoria como recurso de análise (Sá; Azevedo, 2015).

A pesquisa foi aprovada pelo Comitê de Ética do Instituto Nacional de Saúde da Mulher, da Criança e do Adolescente Fernandes Figueira, da Fundação Oswaldo Cruz (IFF/Fiocruz). O Termo de Consentimento Livre e Esclarecido (TCLE) foi utilizado em todos os casos.

\section{Tabelaı - Perfil das crianças selecionadas}

\begin{tabular}{|c|c|c|c|c|c|c|}
\hline Criança & Idade & Diagnóstico & $\begin{array}{c}\text { Equipe } \\
\text { responsável }\end{array}$ & $\begin{array}{l}\text { Dependência } \\
\text { tecnológica }\end{array}$ & Mãe & $\begin{array}{l}\text { Tempo de } \\
\text { internação }\end{array}$ \\
\hline A & 1 ano e 2 meses & $\begin{array}{c}\text { Tetralogia de Fallot; atresia } \\
\text { de laringe; síndrome } \\
\text { de Prune Belly; bexiga } \\
\text { neurogênica. }\end{array}$ & Equipe I & $\begin{array}{l}\text { Gastrostomia e } \\
\text { traqueostomia }\end{array}$ & Aurora & 1 ano e 4 meses \\
\hline B & 7 meses & Fibrose cística & Equipe I & $\begin{array}{c}\text { Oxigenoterapia } \\
\text { com cateter }\end{array}$ & Bruna & 3 meses \\
\hline C & I ano e 6 meses & Síndrome do intestino curto & Equipe 2 & $\begin{array}{c}\text { Gastrostomia } \\
\text { e nutrição } \\
\text { parenteral }\end{array}$ & Carolina & I ano e 7 meses \\
\hline D & 8 anos & Mucopolissacaridose & Equipe 2 & $\begin{array}{l}\text { Gastrostomia e } \\
\text { traqueostomia }\end{array}$ & Dalva & 4 meses \\
\hline
\end{tabular}

Nota: todos os nomes são fictícios. 


\section{Resultados e discussão}

\section{Caracterização e dinâmica da unidade de pacientes internados}

O aumento de internações de pacientes pediátricos com CCC e dependentes de tecnologia nos últimos oito anos da UPI foi um fator importante na dinâmica da unidade e expressa a mudança que vem se passando no campo do cuidado pediátrico (Costa; Gomes; Pinto, 2011).

A UPI tem quatorze leitos, todos ocupados no momento da pesquisa, divididos em sete boxes. A unidade dispõe de cinco médicos tutores e recebe seis residentes de medicina que permanecem na UPI em períodos de dois meses para acompanhamento de todos os pacientes internados. Enfermeiros e técnicos de enfermagem atuam em todos os casos. Outros profissionais constituem uma equipe multiprofissional e atendem segundo demanda e especificidade de cada paciente. No período de observação atuavam três fisioterapeutas, uma nutricionista, uma fonoaudióloga, uma assistente social, uma farmacêutica, duas terapeutas ocupacionais e uma psiquiatra. Estes profissionais supervisionam residentes de suas respectivas especialidades na UPI. No período do estudo havia um total de 40 profissionais no setor.

Quatro vezes por semana ocorrem rounds com a maior parte dos médicos, residentes e alguns representantes de outras categorias, que discutem as condições clínicas dos pacientes, prescrições, pedidos de exames e a intervenção de outros especialistas. Uma vez por semana, o round, denominado multiprofissional, ocorre com as categorias atuantes já mencionadas. Os médicos têm grande representatividade numérica em relação aos demais profissionais e assumem liderança nessas discussões.

Pela manhã a enfermaria é agitada pelas visitas clínicas. Os procedimentos vão da higiene à avaliação dos pacientes pelos profissionais.

Os familiares participam ou produzem alguns cuidados dos seus filhos como banho, aspiração de vias aéreas e alimentação. À tarde o movimento é menor. Nos fins de semana há menos profissionais e acompanhantes das crianças.
A maioria dos pacientes com CCC têm longos períodos de internação na UPI. Com o tempo, as mães passam a utilizar a linguagem técnica dos profissionais, embora possam não saber exatamente o que significa cada termo. Durante a internação, elas recebem orientações sobre os procedimentos técnicos nos cuidados com sua criança, tais como: a alimentação, por vezes, administrada pela gastrostomia; a higiene, que exige o cuidadoso manejo de acessos venosos e dos orifícios não naturais da traqueostomia e da gastrostomia; a administração de medicações e aspiração de vias aéreas. Tarefas complexas são transmitidas às mães dos pacientes, à medida que as condições de saúde da criança permitam; inicialmente sob orientação e supervisão dos técnicos, e depois com maior autonomia. A proximidade de alta hospitalar intensifica a certificação dessa assimilação de cuidados mais técnicos.

\section{Familiares e profissionais: protagonismo $e$ interações}

O contato da família com os profissionais acontece diariamente no decorrer do processo assistencial e pode viabilizar troca de informações sobre a criança entre os atores. A equipe médica é representada pelos residentes. A enfermagem é a categoria que mais tem contato com pacientes e familiares, em função dos numerosos procedimentos diuturnos necessários. As visitas das demais categorias acontecem preferencialmente de manhã, antes das discussões dos casos pela equipe, para que se tenha uma atualização dos quadros clínicos das crianças. Embora o contato profissionalfamiliar deva envolver o acolhimento e a escuta às demandas e necessidades da família, percebeuse a fragmentação e as limitações nessa relação. Algumas mães apontaram que esse contato é feito com objetivo de informar o estado clínico da criança e os procedimentos e medicamentos que serão realizados.

Eles [residentes médicos e demais profissionais] olham, reparam como que ele [paciente] tá, depois vão conversar e vem me avisar o que vai fazer, o que não vai fazer. Se for passar algum remédio eles 
me avisam antes, pra depois ele começar a tomaro remédio. (Bruna)

No entanto, na perspectiva da clínica ampliada e do desenvolvimento de uma clínica dos sujeitos (Campos; Amaral, 2007), compreende-se que os problemas de saúde estão encarnados em indivíduos, com dimensões sociais e subjetivas além da biológica. O contexto de vida de cada paciente deve ser conhecido, assim como devem ser identificadas suas redes de apoio e dados da história de vida, como forma de conhecer os fatores de risco e de proteção das famílias (Campos; Amaral, 2007).

A família de um paciente grave é social e subjetivamente afetada. Seu acompanhante maneja diferentes pressões próprias à hospitalização, somadas às do seu universo social e familiar exterior. A mãe do paciente B afirma: A gente tá sofrendo muito porque ele tá cinco meses internado, vão fazer seis e é muito ruim ficar longe da família (Bruna). No entanto, questionada durante a entrevista se havia conversado sobre isso com algum profissional, Bruna diz que não, se retrai e com os olhos cheios de lágrimas diz: Eu não sei conversar muito bem sobre isso.

As mães têm maior ou menor facilidade para expressar seu sofrimento, assim como os profissionais têm diferentes habilidades interativas individuais. Quando a mãe tem uma atitude atenta e crítica às decisões médicas, é ela quem, na prática, estimula a maior interação com o profissional, permitindo que, na corresponsabilidade, opiniões baseadas em sua observação privilegiada da criança contribuam para o tratamento:

Ela [criança] estava fazendo ânsia de vômito, aí eu falei pra doutora $M$ que eu achava melhor que [a dieta] fosse um pouquinho mais devagar porque todo dia aumentavam e ela não estava aceitando. Aí, ela [médica] falou: "tá bom, então". $\varepsilon$ foi aumentando a cada semana. (Carolina)

O protagonismo da mãe e a escuta sensível do profissional contribuíram para um ajuste do tratamento da criança. Ayres (2006) chama atenção para a necessidade de ampliação do horizonte normativo e valorização do saber não técnico no cuidado em saúde, favorecendo justamente o reconhecimento e a inclusão da família.

Observamos diferentes posições micropolíticas e subjetivas dos familiares, variando da submissão ao prescrito, à atitude assertiva e interpelativa, expressando diferentes condições de vocalização e consciência de seus direitos.

Entre os profissionais, constatamos posicionamentos variados, desde o uso da comunicação unidirecional, do tipo informativo, evidenciado na fala de uma mãe, Bruna, até uma capacidade de acolhimento e escuta que mescla habilidades e sensibilidades individuais. A seguir, um fragmento que expressa um contexto de compreensão e escuta sensível do familiar:

Residente médica: Você tem outros filhos?

Aurora: Não.

Residente médica: Então é atenção exclusiva!

Aurora ri e diz: tem que ser. Eu tava aqui falando pra ela de ter um estetro [estetoscópio] em casa e noção de primeiros socorros, o que você acha?

Residente médica: Eu acho bom, mas você consegue perceber quando ele tá mais cansado só de olhar. Essa informação você pode dar pro pediatra que já ajuda.

Embora os afetos estejam presentes no acompanhamento clínico, observou-se, nos encontros entre médicos tutores e residentes, uma ênfase na aprendizagem dos aspectos biomédicos, em detrimento de uma visão mais integral do paciente. Um exemplo é apontado a seguir. De acordo com a dinâmica da unidade, o residente pode avaliar diariamente um paciente diferente, visando ampliar seus conhecimentos. No entanto, esse processo de trabalho não favorece o vínculo entre o profissional, o paciente e seus família. Há uma preocupação dos tutores com a exposição contínua do residente médico ao sofrimento no cuidado de um mesmo paciente grave. Desta forma, o vínculo com pacientes e familiares, embora reconhecidamente importante, é visto também 
como fator de risco que amplifica o sofrimento psíquico, de difícil manejo pela equipe.

Médica tutora, refere-se a um paciente: Ele está muito abatido, está murcho. Residente: Ele está oscilando, há dois dias o vi no plantão e ele também estava abatido. Tutora: Não ébom você ser a única pessoa que tira o sangue dele. Você acha que eu não me poupo? Deixa outra pessoa tirar o sangue dele. (silêncio e prossegue): Você não é obrigada a vê-lo todo dia, você vai porque você gosta dele. A residente chora. Observação da pesquisadora: Embora outra profissional tenha assinalado a importância do que acontecia, não me pareceu que a residente tenha sido acolhida pelo grupo. (Diário de Campo - registro do round)

O cuidado com a criança gravemente enferma coloca os profissionais de saúde em contato com os limites da vida e do curar, mediante questões que envolvem a dimensão intersubjetiva do cuidar (Azevedo; Sá, 2013). O encontro assistencial inclui o corpo e a subjetividade de profissionais e usuários, conforme discute Campos (2005) e, no caso estudado, envolve também a impossibilidade de cura, o contato com a fragilidade da vida e situações de desamparo vividas pela criança. A criança representa esperança, o olhar para o futuro. Portanto, o encontro com a criança gravemente doente impõe um confronto com uma dimensão do real em suas possibilidades traumáticas, implicando uma experiência desestabilizante, que demanda um trabalho de elaboração psíquica, de trânsito entre o imaginário e o real (Ansermet, 2003), nem sempre possível para os profissionais.

Este ambiente, marcado por uma situação extrema de desamparo psíquico e biológico, desvenda para todos a precariedade, com corpos em dependência, submetidos ao aparato tecnológico, num contexto difícil para o desenvolvimento de processos de simbolização e elaboração tanto pelos pais quanto pelos trabalhadores, configurando-se causa do sofrimento profissional (Ansermet, 2003). A partir dessa leitura, podemos compreender que a construção de vínculo e integralidade do cuidado envolvem processos intersubjetivos complexos, não passíveis de normatização e sempre constituem um desafio de manejo para profissionais.

\section{Dispositivos de gestão do cuidado e o plano de tratamento}

Na UPI, o dispositivo central para gestão clínica dos casos é o round, encontro entre profissionais para discussão dos casos, geralmente coordenados por médicos, em que surgem, além da complexidade clínica dos casos, dilemas socioeconômicos e emocionais que exigem conhecimentos e difíceis manejos. No entanto, essas questões raramente foram tema em suas formações. Por causa da complexidade dos casos e das mudanças constantes no estado clínico dos pacientes, as decisões não se restringem aos rounds. Trocas de mensagens por meios eletrônicos mantêm os profissionais em contato, ultrapassando o ambiente da unidade e ampliando as discussões de condutas, numa demonstração de investimento afetivo, zelo e responsabilidade com os pacientes (Backes; Azevedo, 2017).

O trabalho multiprofissional em equipe, na perspectiva da integralidade, tem se mostrado um desafio para a gestão dos serviços de saúde (Pinheiro; Barros; Mattos, 2007) e se apresenta como nó crítico, exigindo que os profissionais sustentem uma relação de reciprocidade, demandando engajamento, corresponsabilidade e solidariedade (Pinheiro; Barros; Mattos, 2007). A presença de múltiplos integrantes na equipe expõe cada um às ideias, opiniões e desejos do outro, promovendo um exercício ainda difícil para a maioria dos profissionais, pouco habituados ao compartilhamento de decisões (Backes; Azevedo, 2017). É neste campo de tensões que as possibilidades e limites de aprofundamento de questões subjetivas e sociais dos pacientes e seus familiares podem tornarse objeto para os profissionais. Assim, o próprio amadurecimento do trabalho em equipe deve ser visto como um caminho importante para abertura de mais espaço para os familiares.

As reuniões dos profissionais com as famílias, durante o período dessa pesquisa, ocorreram apenas nas circunstâncias imprescindíveis, como: na alta hospitalar com home care, com o Programa de Atendimento Domiciliar Interdisciplinar; nos casos de indicação de transplante de órgãos; na transferência para outros serviços e nos casos de crianças com perspectivas muito limitadas de tratamento. Tais reuniões pareceram essenciais para consideração 
do contexto sociofamiliar, pois deslocam o cuidado de um lugar mecânico, potencializando o vínculo e ampliando a clínica (Campos, 2012).

A comissão de cuidados paliativos é outro dispositivo de gestão do cuidado existente, que pode favorecer a mediação entre profissionais e familiares. Essa comissão é multiprofissional e responsável pelo acompanhamento de situações de risco iminente de morte de pacientes, requerendo um pacto de confiança entre os atores, que contemple também o encaminhamento intersubjetivo dos dilemas clínicos relativos ao fim da vida.

Reconhecendo a importância de um processo de concertação em torno do plano de cuidados, o hospital incluiu, desde 2012, em suas metas de planejamento, o desenvolvimento de projetos terapêuticos singulares, apoiado nas orientações da PNH, para um planejamento de ações em saúde pautado por um "processo de construção coletiva envolvendo, necessariamente, o profissional/equipe de saúde e o(s) usuário(s) em torno de uma situação de interesse comum" (Brasil, 2010, p. 94), privilegiando o compartilhamento das questões em saúde, com pactuação coletiva dos objetivos, análise das estratégias possíveis, implicação das pessoas envolvidas e planejamento das ações. Em nosso estudo foi possível reconhecer a complexidade do processo organizacional e intersubjetivo para promover tal mudança. Não foram observados projetos terapêuticos singulares nos moldes preconizados pela $\mathrm{PNH}$, mas sim esforços para tratar coletivamente os planos de tratamento.

\section{Participação familiar: singularização $e$ instrumentalização do outro no cuidado}

No contexto da clínica ampliada em saúde a autonomia é entendida como capacidade dos indivíduos de lidar com suas redes de dependências, de agirem sobre si mesmos e sobre o meio em que estão inseridos (Campos; Campos, 2012). Neste estudo, as mães aprendem algumas técnicas, adquirindo mais autonomia e aumentando, gradualmente, sua responsabilidade nos cuidados da criança, ao mesmo tempo em que compensam a falta de profissionais na enfermaria.

Ficou subtendido que a mãe entra no circuito de afazeres junto à criança e é inserida na divisão de tarefas como apoio à equipe de enfermagem. Se por um lado, assumir essas funções dá poder à mãe como agente central do cuidado, concomitantemente, exige dela uma superação afetiva na lida com o corpo do filho adoecido, posicionando-a entre o exercício de um direito e a pressão da gestão dos cuidados.

Para a criança, é a mãe quem melhor reassegura a continuidade psíquica, especialmente num momento de descontinuidades do ambiente (Winnicott, 1994), como o da internação hospitalar. É preciso compreender que o contexto em que um filho é portador de doença grave é traumático e delicado para os familiares, sendo necessário um período de descanso das acompanhantes para recomposição física e emocional para terem condições de contribuírem nesses cuidados (Pereira, 2016).

Ao mesmo tempo, um dos requisitos para a alta hospitalar é a garantia de segurança no domínio de algumas técnicas por parte do cuidador, para a continuidade do tratamento domiciliar. A ampliação da autonomia teria a função de reforçar a valorização dos sujeitos na clínica (Collet; Rocha, 2004) (Campos; Campos, 2012). Entretanto, o treinamento técnico adquirido do conhecimento e da experiência provoca uma sobrecarga para o acompanhante no cotidiano hospitalar (Collet; Rocha, 2004). Assim, esta investigação mostra os paradoxos e tensões constantes em que se envolve o familiar, com suas capacidades, disposições e limites singulares. A pesquisa também reconhece o lugar de sujeito de cada familiar no cotidiano de reelaboração e implementação do plano de cuidados.

\section{As mães, os cuidados técnicos e a maternagem}

Para analisar o papel desempenhado pelos atores no cuidado com a criança no contexto de alta complexidade tecnológica, recorremos à perspectiva psicanalítica do cuidado. Figueiredo (2009, p. 125) compreende o cuidar como tarefa de todos na condição humana, incluindo a possibilidade de construção de "um sentido de vida e das vicissitudes de sua existência”. O autor busca, pela sistematização das contribuições da psicanálise, pensar uma teoria geral do cuidado, aplicável a outros campos de conhecimento, como a educação e a saúde. Os agentes cuidadores, sejam pais ou 
profissionais, podem estar presentes a partir de duas modalidades: de forma implicada ou reservada.

A presença implicada exige uma postura atuante e comprometida de quem aposta subjetivamente na pessoa cuidada, envolvendo funções subjetivas, como acolher, reconhecer e interpelar. Seriam funções psíquicas de sustentação ou holding, que podem ser oferecidas por familiares ou profissionais de saúde com ações de acolhimento que oferecem "continuidade na posição simbólica do sujeito no mundo" (Figueiredo, 2009, p. 125). Neste estudo, constatamos que, na prática, as mães assumem as responsabilidades do cuidado, mesclando o papel materno às atividades técnicas.

Essas mães demonstram que o cuidar vai além da concepção biomédica de oferta de atividades mecânicas e prescritas. Elas oferecem, com sua presença implicada, acolhimento, afeto e zelo no cuidado dos filhos, num contexto intersubjetivo de comunicação primitiva (Winnicott, 1994), mesmo inseridas num ambiente altamente tecnológico. As mães desempenham o cuidado de forma afetuosa e desejante, voltando-se simultaneamente ao aprendizado de habilidades que se assemelham ao de uma técnica de saúde para lidar com todos os procedimentos.

Numa trama complexa de atividades técnicas e tarefas afetivas da maternagem, realçamos, apoiadas em Figueiredo (2009, p. 141), que, além da presença implicada, é fundamental a presença em reserva dos agentes. É importante que o cuidador se mantenha disponível, mas sem ter necessariamente ações de interferência, mostrando "a sabedoria de ausentar-se e moderando seus afazeres”. É preciso cuidar de si, deixar-se cuidar pelo outro, destacando que "a mutualidade expressa um equilíbrio ético fundamental” (Figueiredo, 2009, p. 141). É desejável, segundo o mesmo autor, que ambas as formas, implicada e reservada, estejam presentes e em equilíbrio.

Nesta investigação observou-se a preponderância das mães em uma atitude de implicação permanente. Hipoteticamente, um funcionamento fruto do confronto com a doença grave do filho. No entanto, supomos que a dificuldade de se afastar e descansar advém também da pouca definição quanto à divisão de tarefas entre elas e a enfermagem, impondo uma rotina extensa. Se tal papel técnico por parte das mães propicia uma capacitação pessoal para o momento da desospitalização, ao mesmo tempo parece funcional para a organização do trabalho no setor. Talvez um dos motivos para demandas tão intensas de atividades das mães possa ser um contingente reduzido de enfermagem. Embora essa questão não tenha sido explicitada pelos profissionais, durante a observação foi percebido que, em momentos de maior intensidade na rotina de cuidados, o número de técnicos de enfermagem presentes era pequeno perante o número de pacientes e para atender solicitações de suporte feitas pelas mães. A atitude de extrema implicação por parte das mães também se origina na insegurança em relação ao ambiente no qual as tecnologias duras (Merhy, 2002), responsáveis pela manutenção da vida dos seus filhos, podem falhar por si só ou pela insuficiência, sentida por elas, de trabalhadores para exercer vigilância. Assim, há dificuldades em se estabelecer um ambiente de confiabilidade, no sentido adotado por Winnicott (1994), de temor pela gravidade e complexidade do cuidado e pelo risco real de morte.

Assumir essas funções na rotina de cuidados pode ser tão intenso que, por vezes, restam às mães poucas horas de sono. No caso de Aurora, que desempenha tarefas que lhe demandam participação ativa e padronizada:

Ele faz o cateterismo de seis em seis horas, tem os puffs de Sabultamol e Beclometasona. Beclometasona de doze em doze e Sabultamol de quatro em quatro. Eu acordo seis da manhã, aívem aspiração, nebulizo, aspiro e puff. $\varepsilon$ cateterismo que é o mais demorado. Aífico nesse ciclo durante o dia. O último ciclo dele vai terminar as duas da manhã. Então, resumindo, eu vou dormir todo dia as $2 h$ e acordo às 6h. (Aurora)

Surge outra questão intersubjetiva, uma fantasia que assombra as mães e favorece o excesso de implicação. Se elas não participam, como entendem ser esperado pela equipe, podem não ser vistas como boas mães, sendo subjetivamente capturadas pela tentativa de adaptação às demandas do 
ambiente hospitalar, de forma enrijecida e sem espontaneidade.

O reconhecimento do entrelaçamento das funções técnicas e de maternagem favorece, por um lado, a vitalidade e autonomia da mãe, mas, por outro, produz angustia e é fonte de alta exigência psíquica. Assim, depreende-se que a demanda institucional da participação das mães na realização das atividades técnicas precisa considerar os aspectos subjetivos aqui analisados.

\section{Considerações finais}

Observou-se que nem sempre os contextos de vida das famílias e a dimensão subjetiva do sofrimento delas foram suficientemente apreendidos pelos profissionais de saúde. Por vezes, as mães foram vistas como instrumento de cuidado, reduzindose seu espaço singular como sujeito. Dificuldades institucionais e sobrecarga do serviço interferem no vínculo entre esses atores, somadas às limitações pessoais dos profissionais na lida com o sofrimento humano e no reconhecimento da singularidade de cada caso. No entanto, momentos de escuta sensível pelos profissionais estiveram presentes. Observouse ainda que a dinâmica do cuidado, ao envolver a participação de múltiplos profissionais e a rotatividade dos residentes, contribui para sua fragmentação.

As mães incorporam tarefas técnicas da rotina da enfermagem, sentindo-as como de sua responsabilidade, mas acrescentam o zelo e o carinho inerentes à maternagem, diferenciando o cuidado de um fazer impessoal. Embora a presença contínua da família seja incentivada como um direito e por sua importância emocional para o paciente, devemos considerar que a instituição possa estar demandando sua presença e atuação no cuidado técnico num ritmo além do recomendado para a saúde e equilíbrio emocional da mãe. A predominante presença das mães como acompanhantes sugeriu-nos uma questão de gênero que, por sua relevância, merece ser aprofundada em futuras pesquisas na área.

Quanto aos processos decisórios relativos aos planos de tratamento, é importante assinalar que não existiam reuniões regulares com participação da família para construção coletiva, execução e reavaliação das ações terapêuticas. Ora a família era informada sobre as decisões estabelecidas, ora era consultada a respeito das decisões mais difíceis. Constatou-se que os planos de tratamento são delineados entre os profissionais nos rounds, processo protagonizado até o momento pelos médicos.

Enfim, como desafio, apontamos a criação de dispositivo de encontro do profissional de referência com a família, que proporcione espaço para a discussão dos aspectos objetivos e subjetivos dos processos de cuidado e que influencie a organização do plano de tratamento e a consideração do contexto social da família. Ressaltamos os aspectos intersubjetivos, sempre presentes no cotidiano do trabalho clínico assistencial, entendendo que, quando são considerados, podem ser valiosos no manejo das situações vividas diante do adoecimento de uma criança. Assim, acreditamos que esta pesquisa traz elementos para refletirmos sobre o papel das mães nas atuais práticas de cuidado e nas que podem ser implementadas na assistência humanizada às famílias de crianças portadoras de doenças crônicas complexas.

\section{Referências}

ANSERMET, F. Clínica da origem: a criança entre a medicina e a psicanálise. Rio de Janeiro: Contracapa, 2003.

AYRES, J. R. C. M. Cuidado e humanização das práticas de saúde. In: DESLANDES, S. F. (Org.). Humanização dos cuidados em saúde: conceitos, dilemas e práticas. Rio de Janeiro: Fiocruz, 2006. p. $49-83$.

AZEVEDO, C. S.; SÁ, M. C. (Org.). Subjetividade, gestão e cuidado em saúde: abordagens da psicossociologia. Rio de Janeiro: Fiocruz, 2013.

BACKES, J. C.; AZEVEDO, C. S. Os paradoxos do trabalho em equipe em um Centro de Tratamento Intensivo Pediátrico (CTI-Pediátrico): explorando as articulações psicossociais no trabalho em saúde. Interface, Botucatu, v. 21, n. 6o, p. 5-8, 2017.

BARUS-MICHEL, J. O sujeito social. Belo Horizonte: PUC-Minas, 2004.

BRASIL. Ministério da Saúde. Humaniza

SUS: Política Nacional de Humanização: a 
humanização como eixo norteador das práticas de atenção e gestão em todas as instâncias do SUS: Documento base. 4. ed. Brasília, DF, 2004.

BRASIL. Ministério da saúde. Cadernos Humaniza SUS. Brasília, DF, 2010. v. 2. (Série B. Textos Básicos de Saúde).

CAMPOS, G. W. S.; AMARAL, M. A. A clínica ampliada e compartilhada, a gestão democrática e redes de atenção como referências teóricooperacionais para a reforma do hospital. Ciência e Saúde Coletiva, Rio de Janeiro, v. 12, n. 4, p. 849$859,2007$.

CAMPOS, R. T. O. O encontro trabalhadorusuário na atenção à saúde: uma contribuição da narrativa psicanalítica ao tema do sujeito na saúde coletiva. Ciência e Saúde Coletiva, Rio de Janeiro, v. 10, n. 3, p. 573-583, 2005.

CAMPOS, R. T. O. Psicanálise e saúde coletiva: interfaces. São Paulo: Hucitec, 2012.

CAMPOS, R. T. O.; CAMPOS, G. W. S. Co-construção de autonomia: o sujeito em questão. In: CAMPOS, G. W. S. et al. (Org.). Tratado de Saúde Coletiva. São Paulo: Hucitec, 2012. p. 669-688.

COHEN, E. et al. Children with medical complexity: an emerging population for clinical and research initiatives. Pediatrics, Washington, DC, v. 127, n. 3, p. 529-538, 2011.

COLLET, N.; ROCHA, S. M. M. Criança hospitalizada: mãe e enfermagem compartilhando o cuidado. Revista Latino-Americana de Enfermagem, Ribeirão Preto, v. 12, n. 2, p. 191-197, 2004.

COSTA, M. T. F.; GOMES, M. A.; PINTO, M. M. Dependência crônica de ventilação pulmonar mecânica na assistência pediátrica: um debate necessário para o SUS. Ciência e Saúde Coletiva, Rio de Janeiro, v. 16, n. 10, p. 4147-4159, 2011.

ENRIQUEZ, E. A organização em análise. Petrópolis: Vozes, 1997.

FIGUEIREDO, L. C. As diversas faces do cuidar: considerações sobre a clínica e a cultura. In: MAIA, M. S. (Org.). Por uma ética do cuidado. Rio de Janeiro: Garamond, 2009. p. 120-141.
GOMES, G. C.; ERDMANN, A. L. O cuidado compartilhado entre a família e a enfermagem à criança no hospital: uma perspectiva para a sua humanização. Revista Gaúcha de Enfermagem, Porto Alegre, v. 26, n. 1, p. 20-30, 2005.

MERHY, E. E. Saúde: a cartografia do trabalho vivo. São Paulo: Hucitec, 2002.

MINAYO, M. C. S. O desafio do conhecimento: pesquisa qualitativa em saúde. São Paulo: Hucitec, 2013.

MOREIRA, M. C. N.; GOMES, R.; SÁ, M. R. C. Doenças crônicas em crianças e adolescentes: uma revisão bibliográfica. Ciência e Saúde Coletiva, Rio de Janeiro, v. 19, n. 7, p. 2083-2094, 2014.

PEREIRA, N. V. P. G. As práticas de cuidado e as relações intersubjetivas entre o profissional de saúde e o paciente pediátrico no contexto de internações prolongadas. 2016. Dissertação (Mestrado em Saúde Pública) - Escola Nacional de Saúde Pública Sérgio Arouca, Fundação Oswaldo Cruz, Rio de Janeiro, 2016.

PINHEIRO, R. Cuidado como um valor: um ensaio sobre o (re)pensar a ação na construção de práticas eficazes de integralidade em saúde. In: PINHEIRO, R.; MATTOS, R. A. (Org.). Razões públicas para integralidade em saúde: o cuidado como valor. Rio de Janeiro: IMS/Uerj, 2007. p. 15-28.

PINHEIRO, R.; BARROS, M. E. B.; MATTOS, R. A. Trabalho em equipe sob o eixo da integralidade: valores, saberes e práticas. Rio de Janeiro: IMS/ Uerj, 2007.

PINHEIRO, R.; SILVA JUNIOR, A. G. A centralidade do usuário na avaliação em saúde: outras abordagens. In: PINHEIRO, R.; MARTINS, P. H. (Org.). Avaliação em saúde na perspectiva do usuário: abordagem multicêntrica. Rio de Janeiro: Cepesc, 2009. p. 37-52.

SÁ, M. C.; AZEVEDO, C. S. Uma abordagem psicossociológica na pesquisa sobre o cuidado em saúde e o trabalho gerencial. In: BAPTISTA, T. W. F.; AZEVEDO, C. S.; MACHADO, C. V. (Org.). Políticas, planejamento e gestão em saúde: abordagens e métodos de pesquisa. Rio de Janeiro: Fiocruz, 2015. p. 219-253. 
TEXEIRA, R. R. Acolhimento num serviço de saúde entendido como uma rede de conversações. In: PINHEIRO, R.; MATTOS, R. (Org.). Construção da integralidade: cotidiano, saberes e práticas em saúde. Rio de Janeiro: IMS/Uerj: Abrasco, 2003. p. 89-111.

TURATO, E. R. Tratado da metodologia da pesquisa clínico-qualitativa: construção teórico- epistemológica, discussão comparada e aplicada nas áreas de saúde e humanas. Petrópolis: Vozes, 2008.

WINNICOTT, D W. A experiência mãe-bebê de mutualidade. In: WINNICOTT, C.; SHEPHERD, R.; DAVIS, M. (Org.). Explorações psicanalíticas: D. W. Winnicott. Porto Alegre: Artes Médicas Sul, 1994. p. 195-202.

\section{Contribuição das autoras}

Todas as autoras contribuíram para a concepção da pesquisa, análise das informações e redação.

Recebido: $28 / 08 / 2017$

Reapresentado: 24/05/2018

Aprovado:14/08/2018 